\title{
Remote sensing of tropical tropopause layer radiation balance using
} \section{A-train measurements}

\author{
D. R. Feldman, ${ }^{1}$ T. S. L’Ecuyer, ${ }^{2}$ K. N. Liou, ${ }^{3}$ and Y. L. Yung ${ }^{1}$ \\ Received 20 March 2008; revised 16 July 2008; accepted 8 August 2008; published 12 November 2008.
}

[1] Determining the level of zero net radiative heating (LZH) is critical to understanding parcel trajectory in the Tropical Tropopause Layer (TTL) and associated stratospheric hydration processes. Previous studies of the TTL radiative balance have focused on using radiosonde data, but remote sensing measurements from polar-orbiting satellites may provide the relevant horizontal and vertical information for assessing TTL solar heating and infrared cooling rates, especially across the Pacific Ocean. CloudSat provides a considerable amount of vertical information about the distribution of cloud properties relevant to heating rate analysis. The ability of CloudSat measurements and ancillary information to constrain LZH is explored. We employ formal error propagation analysis for derived heating rate uncertainty given the CloudSat cloud property retrieval algorithms. Estimation of the LZH to within approximately 0.5 to $1 \mathrm{~km}$ is achievable with CloudSat, but it has a low-altitude bias because the radar is unable to detect thin cirrus. This can be remedied with the proper utilization of Cloud-Aerosol Lidar and Infrared Pathfinder Satellite Observations (CALIPSO) lidar backscatter information. By utilizing an orbital simulation with the GISS data set, we explore the representativeness of non-cross-track scanning active sounders in terms of describing the LZH distribution. In order to supplement CloudSat, we explore the ability of Atmospheric Infrared Sounder (AIRS) and Advanced Microwave Scanning Radiometer-EOS (AMSR-E) to constrain LZH and find that these passive sounders are useful where the cloud top height does not exceed $7 \mathrm{~km}$. The spatiotemporal distributions of LZH derived from CloudSat and CALIPSO measurements are presented which suggest that thin cirrus have a limited effect on LZH mean values but affect LZH variability.

Citation: Feldman, D. R., T. S. L'Ecuyer, K. N. Liou, and Y. L. Yung (2008), Remote sensing of tropical tropopause layer radiation balance using A-train measurements, J. Geophys. Res., 113, D21113, doi:10.1029/2008JD010158.

\section{Introduction}

[2] Stratospheric water vapor has been and continues to be the subject of scientific study owing to its strong influence on the Earth's radiation budget and its impact on catalytic ozone destruction. The observed values of stratospheric water vapor in the vicinity of the tropical tropopause [e.g., Webster et al., 1994; Weinstock et al., 1994; May, 1998; Paul et al., 2001; Baer et al., 2002; Vömel et al., 2007] are significantly lower than would be expected from the Clausius-Clapeyron constraint imposed by the mean cold-point tropopause temperature [Michelsen et al., 2000]. Discerning the relative roles of convection and radiation in the determination of the transport of water vapor from the troposphere to the stratosphere remains an

\footnotetext{
${ }^{1}$ Division of Geological and Planetary Sciences, California Institute of Technology, Pasadena, California, USA.

${ }^{2}$ Department of Atmospheric Science, Colorado State University, Fort Collins, Colorado, USA.

${ }^{3}$ Department of Atmospheric and Oceanic Sciences, University of California, Los Angeles, California, USA.
}

Copyright 2008 by the American Geophysical Union. 0148-0227/08/2008JD010158\$09.00 area of active scientific discussion, as does explaining observed trends therein [i.e., Rosenlof et al., 2001]. The tropical tropopause layer (TTL) is of particular importance to this discussion because it is thought to contribute substantially to stratospheric water vapor transport. This layer is conventionally defined as a transition region between radiative-convective and radiative equilibrium, and because there is very little latent heating above $12 \mathrm{~km}$ in the tropics, parcel vertical velocity and radiative heating are closely coupled in the TTL. In this region, net radiative heating is negative at lower altitudes due primarily to water vapor cooling, but is positive at higher altitudes owing primarily to ozone heating. In between, there is a level (or levels) of zero net heating (denoted here and by others as LZH) which is the separation level that determines whether uplifted parcels ascend or descend. Determining the altitude of this level and characterizing its spatial and temporal variability are crucial to elucidating the relative strength of the mechanisms that control stratospheric $\mathrm{H}_{2} \mathrm{O}$ transport.

[3] The importance of the TTL has been recognized for some time as a mechanism for stratospheric control [Holton et al., 1995] and was described in detail by Highwood and Hoskins [1998]. The latter paper qualitatively discussed the 
roles of convection and diabatic heating in determining stratosphere/troposphere transport. Subsequent work has focused on providing a detailed quantitative description of these and other possible processes and in the meantime, a couple of different working definitions of the TTL have emerged, many of which describe the TTL as bounded on the bottom by the LZH and on the top by the cold-point tropopause [see Fueglistaler et al., 2007]. In recent years, several models have emerged to enhance understanding of TTL transport processes. Sherwood and Dessler [2000] presented a hypothesis for the excessive dehydration of the stratosphere relying on vertical and horizontal mixing in the tropopause and a multistep process of convection, advection, and ascent for parcels to cross from the troposphere to the stratosphere. Holton and Gettelman [2001] proposed that horizontal transport in the TTL, facilitated by long particle residence times, is responsible for the observed excessive dehydration, and that the tropical Western Pacific Ocean exerts a disproportionate impact on this dehydration. However, Sherwood and Dessler [2001] presented a model that favored convection as a description of TTL $\mathrm{H}_{2} \mathrm{O}$ transport. Later, Sherwood et al. [2003] found that active convection is a very significant process for governing parcel dehydration and the altitude and temperature of the tropical cold point tropopause.

[4] Given the importance of radiative heating rates toward ultimately determining whether a parcel ascends or descends, several authors have analyzed heating rates from a few different perspectives. The importance of radiative heating in the TTL and the differential heating associated with varying cloud configurations were described by Hartmann et al. [2001]. This work found that the vertical distribution of clouds may be key to the explanation of the observed stratospheric dehydration because the radiative influence of a cirrus cloud layer is dependent upon the convective cloud top height. The actual determination of $\mathrm{LZH}$ is a nontrivial process that has only recently been explored from a process perspective. Gettelman et al. [2004] broached the importance of a detailed evaluation of radiation balance in the TTL and used temperature and water vapor profiles from radiosondes to do so. This work found that $\mathrm{LZH}$ varied by about $500 \mathrm{~m}$ from measurement to measurement. Additionally, Corti et al. [2005] determined vertical mass flux in the tropics from radiative heating rate calculations and found that it is a strong function of cloud cover. This paper, however, found that the transition from radiative cooling to heating occurs at lower altitudes where clouds are present, as compared to clear-sky cases, thereby contradicting the results of previous studies. Further work by Gettelman and Birner [2007] began the process of comparing TTL climatology and variability as determined through radiosonde observations with circulation model representation of TTL processes. This work found that the large-scale mean state and variability of the TTL are well represented by the models despite heavily parameterized cloud processes.

[5] Heating rate profiles have also been determined at the Atmospheric Radiation Measurement (ARM) program's Tropical Western Pacific sites [Stokes and Schwartz, 1994] using a combination of radiosonde and millimeterwavelength cloud radar data [McFarlane et al., 2007; Mather et al., 2007]. The results were compared with those produced by the Community Atmosphere Model (CAM) model and it was found that CAM models capture some, but not all, of the heating rate variability. Also, Fueglistaler and $F u$ [2006] used European Centre for Medium-Range Weather Forecasting 40-year reanalysis (ECMWF ERA-40) trajectory analysis to understand the processes that control stratospheric water vapor variability and found reasonable agreement with assessments from satellite-based measurements. Norton [2001] analyzed longwave heating in the tropical lower stratosphere using ECMWF analyses. This work found that ozone IR heating displayed a high degree of variability and was anticorrelated with tropospheric cooling rates, suggesting the importance of upper tropospheric clouds in governing heating rates near the TTL.

[6] Most of the previous heating rate analyses have focused on utilizing radiosonde data or other data of a limited spatial to determine TTL properties, but satellitebased remote sensing measurements, if properly utilized, can introduce a much more detailed spatial analysis of those quantities which are ultimately necessary for characterization of the LZH level. The availability of a new and unprecedented set of measurements from the NASA Earth Observing System A-Train Constellation [Asrar and Dozier, 1994], including AIRS [Aumann et al., 2003] and CloudSat [Stephens et al., 2002] may be able to reduce uncertainties in the determination of this level and provide a more spatially detailed analysis of TTL radiation balance. However, this approach will only be successful if the remote sensing measurements are evaluated within a retrieval framework that captures the true horizontal, vertical, and temporal variability in the TTL radiative balance.

[7] In order to address the feasibility of applying remote sensing measurements to analyze the TTL radiation balance, we first present a description of several CloudSat products and discuss the estimation of their uncertainties. Next, determination of the LZH from CloudSat and CALIPSO products is discussed, and the spatiotemporal distribution of LZH values derived from data covering July 2006 to July 2007 is presented. Subsequently, the ability of passive sounding data to constrain the LZH is explored. After that, orbital simulation experiments are performed to test the representativeness of simulated along-track LZH sampling from CloudSat. Finally, seasonally averaged maps of LZH mean and variability derived from CloudSat and CALIPSO products are presented.

\section{CloudSat Heating Rates}

[8] As part of the NASA Earth Observing System A-Train, the CloudSat satellite is a polar-orbiting, sun-synchronous platform on which the CloudSat Profiling Radar measures along-track radar reflectivity at $94 \mathrm{GHz}$ with a minimum sensitivity of $-31 \mathrm{dBz}$ (see Meneghini and Kozu [1990] for an introductory discussion of space-borne cloud radar). Partial attenuation by hydrometeors at this frequency allows for the characterization of cloud vertical distribution over a broad range of observed cloud systems. Several mission products are derived from the radar reflectivity at $240 \mathrm{~m}$ vertical resolution and are directly relevant to a TTL radiative heating/cooling analysis. The $2 \mathrm{~B}-\mathrm{CWC}-\mathrm{RO}$ product, for example, contains cloud water content profiles, and the 2B-FLXHR product provides radiative fluxes and heating 
rates consistent with these water contents. However, owing to potential uncertainties in these products, their nature must be explored in the context of their ability to constrain radiative heating rates in the TTL.

[9] The algorithms for generating $2 \mathrm{~B}-\mathrm{CWC}$ ice and liquid cloud profile products from radar reflectivity measurements are described by R. T. Austin (Level 2B Radar-only Cloud Water Content (2B-CWC-RO) process description document, http://www.cloudsat.cira.colostate.edu/ICD/2BCWC/2B-CWC-RO_PD_5.1.pdf) and are based on the works of Benedetti et al. [2003] and Austin and Stephens [2001], respectively. Here, we make use of Release 04 of the radar-only retrievals which only utilize radar reflectivity measurements and a priori data (refer to http://www. cloudsat.cira.colostate.edu for details). The retrieval algorithm assumes that cloud droplet distributions can be reasonably parameterized with a lognormal size distribution so that droplet number count, effective radius, and geometric standard deviation are the three retrieval targets. The retrieval also assumes that cloud droplets are sufficiently small so that they can be effectively treated as Rayleigh scatterers, though this assumption is valid only for nonprecipitating scenes. The cloud phase is determined by using ECMWF analysis information [Rabier et al., 1998] for the observed scene, including temperature, water vapor, and ozone profiles. For those vertical bins when the temperature is less than $-20^{\circ} \mathrm{C}$, ice cloud properties are retrieved, whereas for temperatures exceeding $0^{\circ} \mathrm{C}$, liquid cloud properties are retrieved. In between, both liquid and ice cloud properties are retrieved separately with scaling factors for the two phases which are a linear function of the temperature such that vertical bins at the upper altitudes of the transition zone are mostly ice and those at the lower altitudes are mostly liquid.

[10] Optimal estimation theory [Rodgers, 2000] is employed to balance a priori knowledge of droplet number and effective radius profiles with the information content contained in the measurements through a forward model. Empirical relationships between cloud water content, cloud effective radius, and geometric standard deviation as a function of temperature and pressure from aircraft campaigns are used as a priori constraints [e.g., McFarquhar and Heymsfield, 1997].

[11] The current algorithm for generating fluxes and heating rates at $240 \mathrm{~m}$ vertical resolution from CloudSat measurements and other ancillary products is described by L'Ecuyer et al. [2008]. Briefly: temperature, water vapor, ozone, cloud water content, and cloud effective radius profiles form the inputs to a broadband, two-stream, planeparallel, doubling-adding radiative transfer model. Six shortwave and 12 longwave bands are utilized to produce net shortwave $(0.2$ to $4 \mu \mathrm{m})$ and longwave $(4.55$ to $\infty \mu \mathrm{m})$ fluxes and heating rates using a $\delta$-Eddington and constant hemispheric approximation, respectively. The subsequent analysis also makes use of an experimental fluxes and heating rate product derived from the combination of CloudSat and CALIPSO [Winker et al., 2003] measurements. This new algorithm, that will likely form the basis of a new CloudSat 2B-FLXHR-LIDAR product in the near future, operates identically to the 2B-FLXHR approach, but the revised product also makes use of the CALIPSO vertical feature mask through CloudSat's GEOPROF-LIDAR product [Mace et al., 2007; Marchand et al., 2008] to fill in thin high clouds and low clouds missed by CloudSat. The GEOPROF-LIDAR product is used to define scenes where CloudSat misses high clouds. The raw CALIPSO backscatter observations are then used to determine the integrated optical depth of these clouds and their extinction using the molecular scattering above and below the cloud. This should fall off exponentially with height in the absence of a cloud. The extinction associated with the high clouds that CloudSat does not detect is generally independent of height, latitude, and season, and a representative effective radius $(30 \mu \mathrm{m})$ and the mean ice water path $\left(0.004 \mathrm{~g} / \mathrm{m}^{3}\right)$ are assumed on the basis of extinction observations from lidar data collected from the Canadian Network for the Detection of Atmospheric Change (http:// www.candac.ca). While this approach is clearly approximate in nature, heating rate calculations derived in this manner should statistically capture the impact of these thin clouds quite well to first order (see Kay et al. [2008] for more details).

[12] Parcels in the TTL experience a range of shortwave heating throughout the day which is a strong function of the incident solar zenith angle. Therefore, it is important to consider whether the shortwave heating rates produced by the CloudSat 2B-FLXHR and 2B-FLXHR-LIDAR products derived from 0130 and 1330 local time observations provide appropriate sampling for the diurnal cycle. We tested several different cloud-cover scenarios (e.g., low-level liquid clouds, midlevel liquid clouds, high-level ice clouds, and low-level liquid clouds below high-level ice clouds) with different solar zenith angles and found that by averaging daytime and nighttime orbits, we can produce diurnally averaged shortwave heating to within $5 \%$.

[13] It should be noted that some of the heating rate analysis and associated sensitivity tests presented in this paper do not directly utilize the radiative transfer code used to calculate the 2B-FLXHR. Rather, we use a slightly more refined broadband radiative transfer model: RRTM [Mlawer et al., 1997; Clough et al., 2005]. The differences between the two codes are noticeable in some vertical regions. The codes utilize different water vapor continua models, which affect boundary layer longwave cooling: the 2B-FLXHR algorithm used CKD 2.1 [Clough et al., 1989] whereas RRTM uses MT_CKD 1.0 [Clough et al., 2005]. Future versions of the 2B-FLXHR algorithm may include MT_CKD 1.0. Also, different treatment of intermediate strength bands and overlap lead to discrepancies in heating and cooling rates in the middle stratosphere. In the midtroposphere and upper troposphere lower stratosphere (UTLS) regions, differences generally arise from the 2B-FLXHR treatment of cloud optical properties as gray. This stands in contrast to the treatment in RRTM which employs a wavelength-dependent parameterization for liquid clouds described by Hu and Stamnes [1993] and for ice clouds by Fu et al. [1997]. Potential differences in cloud overlap treatment do not have to be considered here because the CloudSat field-of-view is small enough that the overcast approximation is sufficient. Given the wide range of scenes examined here, however, differences in radiative transfer implementation are not expected to significantly alter the general conclusions reported below.

[14] The current algorithm used to create CloudSat 2BFLXHR products does not include error estimates on fluxes and heating rate products, though this can be accomplished 
(a)

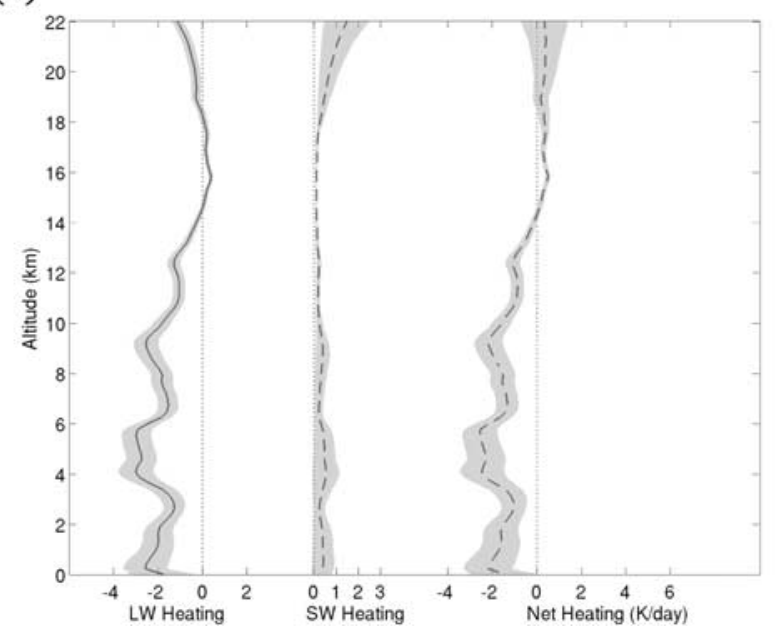

(b)

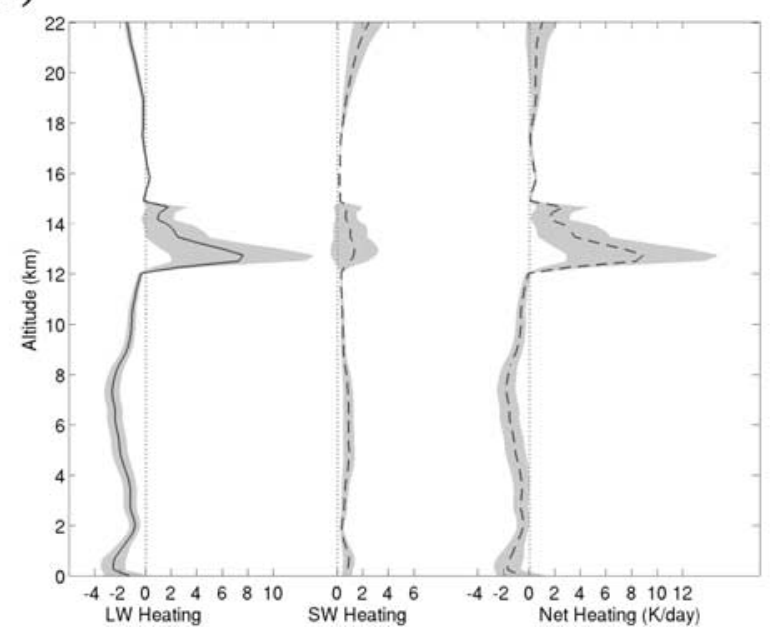

Figure 1. (a) Clear-sky longwave, shortwave, and net radiative heating rate profiles from the 2BFLXHR product for a sample granule on 17 October 2006 at $0116 \mathrm{UT}$ at $0^{\circ} \mathrm{N}$ and $173^{\circ} \mathrm{W}$. Shaded gray indicates uncertainty estimate based on approximate ECMWF uncertainty estimates in $\mathrm{T}, \mathrm{H}_{2} \mathrm{O}$, and $\mathrm{O}_{3}$ profiles. (b) Same as Figure 1a but for profile at $2^{\circ} \mathrm{N}$ and $174^{\circ} \mathrm{W}$ with a cirrus layer of cloud water path $\approx 15 \mathrm{~g} / \mathrm{m}^{2}$ at $14-16 \mathrm{~km}$ with cloud water content uncertainty from 2B-CWC-RO data.

through formal error propagation analysis [Taylor and Kuyatt, 1994; Feldman et al., 2008]. Assuming that the variables relevant to heating rate calculations can be statistically modeled as Gaussian, the uncertainty in the cooling rate profile is given by the following:

$$
\left[\Delta \theta^{\prime}(z)\right]=\sqrt{\sum_{i=1}^{n} \sum_{j=1}^{n} \frac{\partial \theta^{\prime}(z)}{\partial x_{i}} \frac{\partial \theta^{\prime}(z)}{\partial x_{j}} \operatorname{cov}\left(x_{i}, x_{j}\right)},
$$

where $\left(x_{1}, \ldots x_{i}, \ldots x_{j}, \ldots, x_{n}\right)$ represent all of the atmospheric state inputs that are relevant to cooling rate profile calculations at each level, $\theta^{\prime}(z)$ refers to the broadband cooling rate at height $z$, and cov refers to the covariance function. The relevant atmospheric state inputs include the $\mathrm{T}, \mathrm{H}_{2} \mathrm{O}$, and $\mathrm{O}_{3}$ profiles and the cloud water content and effective radius profiles. The $\mathrm{T}, \mathrm{H}_{2} \mathrm{O}$, and $\mathrm{O}_{3}$ profiles from the ECMWF analysis data are used in the 2BFLXHR without error estimates, but it can be reasonably assumed that these data products will have difficulty estimating temperature to better than $1 \mathrm{~K}$ and water vapor and ozone to better than $10 \% \mathrm{vmr}$ at each evenly spaced vertical bin of $240 \mathrm{~m}$. No information is provided to constrain the error covariance of the $\mathrm{T}, \mathrm{H}_{2} \mathrm{O}$, and $\mathrm{O}_{3}$ profiles so that, especially under clear conditions, it may be necessary to utilize the sample covariance of $\mathrm{T}, \mathrm{H}_{2} \mathrm{O}$, and $\mathrm{O}_{3}$ profiles derived from several weeks worth of profiles at the location of interest. Where clouds are present, heating rates are significantly affected in those parts of the profile covered by clouds. Consequently, the uncertainties in cloud water content and cloud effective radius profiles retrieved from CloudSat generally dominate the error budget.

[15] Shortwave and longwave heating rate uncertainties are estimated separately, and the net heating rate uncertainty is derived by combining the two uncertainty calculations using the following formula:

$$
\Delta \theta_{N E T}^{\prime}(z)=\sqrt{\left(\Delta \theta_{S W}^{\prime}(z)\right)^{2}+\left(\Delta \theta_{L W}^{\prime}(z)\right)^{2}}
$$

where $\Delta \theta_{S W}^{\prime}(z)$ is the uncertainty in shortwave heating, $\Delta \theta_{L W}^{\prime}(z)$ is the uncertainty in longwave cooling, and $\triangle \theta_{N E T}^{\prime}(z)$ is the uncertainty in the net heating. Given that the 2B-CWC-RO products regularly report uncertainties of $50 \%$ for cloud water content and cloud effective radius, the error estimate of in-cloud heating rates will be on the order of $50 \%$ of the calculated heating rate. Incloud flux measurements in the course of validation experiments may be useful to govern the development of future CloudSat processing algorithms of 2B-FLXHR products. Figure 1a shows sample longwave cooling, shortwave heating, and net heating rate profiles produced by CloudSat through the 2B-FLXHR product, along with estimates of the uncertainty associated with these products based on temperature uncertainty of $1 \mathrm{~K}$ at each level and water vapor and ozone uncertainty of $10 \%$ of the volume mixing ratio at each level under clear-sky conditions. Figure $1 \mathrm{~b}$ shows the same heating and cooling rate profiles where clouds are present and the estimated uncertainty is strongly affected by the reported CWC uncertainty at each level.

\section{Determination of Zero Net Heating}

[16] In the TTL, there is a transition from net radiative cooling to net radiative heating with increasing altitude, and the LZH is located at a height of approximately $15 \mathrm{~km}$. Because convective clouds rarely ascend into the TTL, heating rates generally change slowly with altitude at a rate of $0.1 \mathrm{~K} / \mathrm{d} / \mathrm{km}$ from around $-0.5 \mathrm{~K} / \mathrm{d}$ at the lower level of 

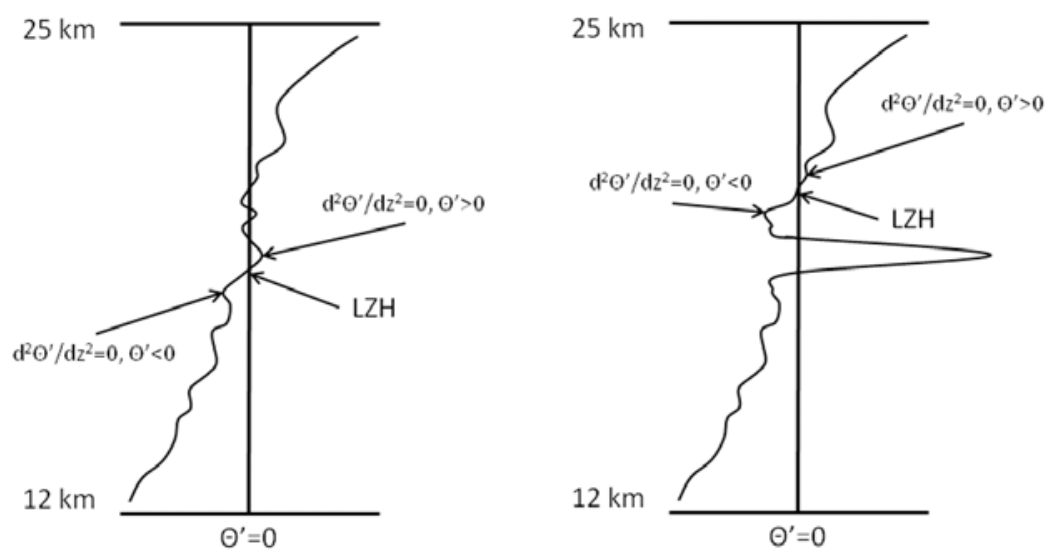

Figure 2. Cartoons depicting the method for determining the LZH altitude given the net heating rate profile. The algorithm chooses the zero point by finding those points of the net heating rate profile where the second derivative is zero and linearly interpolates between the lowest altitude set of points where the net heating is positive and another where the net heating is negative. (left) Qualitative depiction of a typical clear-sky net heating rate profile and (right) a net heating rate profile with a high-altitude cirrus cloud.

the TTL to around $0.2 \mathrm{~K} / \mathrm{d}$ at the cold-point tropopause, which is $\sim 2.5 \mathrm{~km}$ above the LZH level.

[17] There are several atmospheric state quantities that contribute to the location of the LZH level. First, although water vapor dominates radiative cooling in the upper troposphere, $\mathrm{H}_{2} \mathrm{O}$ emission efficiency decreases substantially above $13 \mathrm{~km}$. Water vapor contributes to essentially all of the IR cooling in the TTL $\left(\mathrm{CO}_{2}\right.$ and $\mathrm{O}_{3}$ produce IR heating), though water vapor variability contributes to only about $50 \%$ of net IR TTL heating variability. Second, the vertical temperature structure affects cooling from the $\mathrm{CO}_{2} \nu_{2}$ band, while the $\mathrm{O}_{3}$ profile details are important both for solar heating and IR cooling. Third, solar heating of $\mathrm{CO}_{2}, \mathrm{O}_{3}$, and $\mathrm{H}_{2} \mathrm{O}$ is largely a function of zenith angle with lower zenith angles (maximum daily insolation) leading to lower LZH levels. Fourth, the presence of underlying clouds can impact the LZH in many different ways, primarily by modulating the $\mathrm{CO}_{2}$ and $\mathrm{O}_{3}$ infrared heating, and secondarily by affecting $\mathrm{H}_{2} \mathrm{O}$ rotational band emission. The $\mathrm{LZH}$ is affected by changes in shortwave heating arising from reflection from underlying cloud layers, but this effect is a secondorder correction. Finally, where present, a cirrus layer in the TTL with underlying convective cloud top height below $12 \mathrm{~km}$ will lead to net radiative heating while the same cirrus layer with a higher convective cloud top height will have a net radiative cooling.

[18] A typical clear-sky net radiative heating rate profile has radiative cooling due to water vapor in the lower and middle troposphere which transitions in the upper troposphere and stratosphere to radiative heating due to ozone. The transition region is often marked by a large number of oscillations in net heating about the zero line due to gravity waves. Meanwhile, a typical cloudy-sky net radiative heating rate profile differs from the clear-sky case in that there is large radiative heating at the base and within clouds and strong cooling at the cloud top. Moreover, the presence of an underlying cloud slightly decreases the efficacy of cooling by water vapor in the upper troposphere and significantly decreases IR heating by ozone in the tropopause and lower stratosphere. Owing to the latter effect, the LZH level is raised by a few kilometers by the presence of a cloud. The determination of the LZH level can be ambiguous given the number of oscillations in net heating near the zero-heating level. Nevertheless, the presence of clouds unambiguously diminishes the infrared heating from $\mathrm{O}_{3}$, thereby leading to increased cooling at all layers between the cloud top and the level middle stratosphere.

[19] The determination of the LZH level first requires a net heating rate profile. With this, we must recognize that the determination of the LZH level is nontrivial because, while net heating at $25 \mathrm{~km}$ is positive and decreases at lower altitudes, the net heating rate profile sometimes exhibits a large number of oscillations about the zero line. The LZH searching algorithm first finds the inflection points of the net heating rate profile. Several of the inflection points will have positive net heating and others will have negative net heating. The LZH is determined by linearly interpolating between the lowest altitude set of two inflection points wherein one has a positive net heating and the other a negative net heating. Where clouds are present, only net heating above cloud tops is considered. Uncertainty in the LZH determination for an individual profile is assessed by adding one standard deviation to the net heating rate profile and recalculating the LZH, and then doing the same after subtracting one standard deviation from the net heating rate profile. This process tends to overestimate the uncertainty in the LZH altitude but is practical and computationally efficient. Figure 2 illustrates the process of determining the LZH altitude with a net heating rate profile that oscillates about the zero line in clear-sky and cloudy conditions.

[20] In order to demonstrate the LZH altitude determination with remote sensing measurements, Figures $3 a-3 c$ depicts a scene in the Tropical Western Pacific with several different A-Train measurements. For reference purposes, Figure 3a shows the Cloud Top Height product from MODIS [Platnick et al., 2003] with an overlay of the CloudSat and CALIPSO field-of-view. Figure $3 b$ contains 
(a)

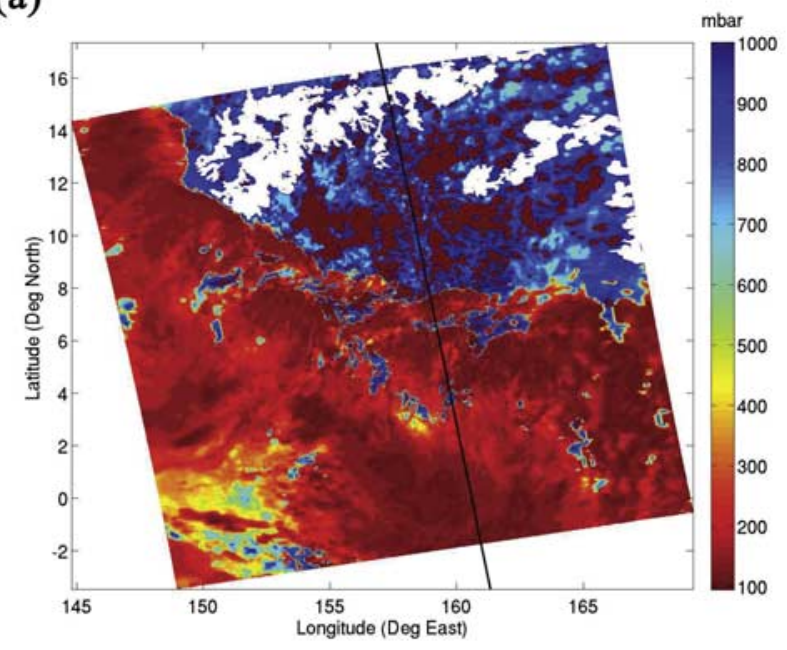

(b)
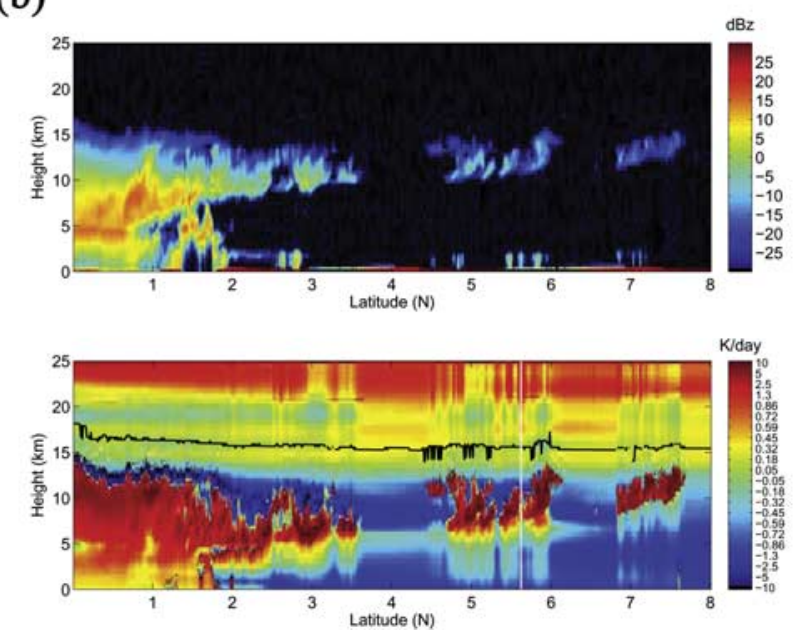

(c)
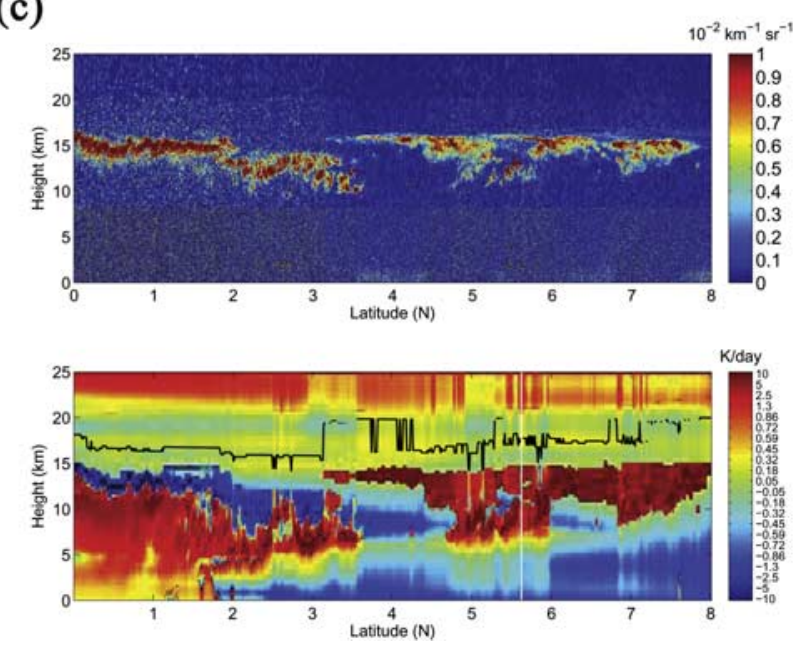

Figure 3. (a) MODIS Cloud Top Temperature granule for 12 January 2007, at 0304 UT from $0^{\circ}$ to $10^{\circ} \mathrm{N}$ and $145^{\circ} \mathrm{E}$ to $165^{\circ} \mathrm{E}$ with a black line denoting ground footprint of the CloudSat and CALIPSO instruments. (b) (top) CloudSat 2B-GEOPROF radar reflectivity for the curtain corresponding to the scene shown in Figure 3a. (bottom) Net radiative heating rate profile curtain derived from the CloudSat 2B-FLXHR product. The overlaid black line indicates the estimation of the LZH level. (c) (top) CALIPSO $532 \mathrm{~nm}$ total attenuated backscatter curtain corresponding to the scene shown in Figures $3 \mathrm{a}$ and $3 \mathrm{~b}$. (bottom) Net radiative heating rate profile curtain from the CloudSat 2B-FLXHR-LIDAR product. The overlaid black line indicates the estimation of the LZH level.

two panels: the top panel shows the CloudSat Radar Reflectivity for a sample granule from 12 January 2007, at 0304 UT. Figure 3b (bottom) shows the 2B-FLXHR net heating rate profiles for the granule. There are a few missing profiles because the processing algorithm currently does not produce heating rate profiles where the CWC product contains null retrieval values. Nevertheless, where there are data, it can be seen that clouds affect net heating rate profiles: at the base of a cloud deck, net radiative heating occurs, while significant net cooling occurs at cloud tops. Also, Figure $3 \mathrm{~b}$ (bottom) shows the estimated location of the $\mathrm{LZH}$, which exhibits small variations from $\mathrm{T}, \mathrm{H}_{2} \mathrm{O}$, and $\mathrm{O}_{3}$ along-track variability but is dramatically elevated by the presence of clouds. Since CloudSat is unable to detect thin cirrus clouds, it is likely that measurements from this instrument will underestimate the LZH level. Merged
CloudSat and CALIPSO cloud water content products will allow for TTL heating rate analysis with less systematic bias. Figure $3 \mathrm{c}$ shows similar curtains as Figure $3 \mathrm{~b}$ but utilizes extra information provided by the CALIPSO instrument. Figure 3c (top) shows CALIPSO's 532-nm total attenuated backscatter of the scene described in Figure $3 \mathrm{~b}$. Whereas the lidar measurements are sensitive to thin clouds, the measurements are unable to describe cloud vertical profiles for thick clouds. Figure 3c (bottom) displays the 2B-FLXHR-LIDAR product for the scene. The ability to detect thin cirrus clouds clearly leads to increased upper tropospheric heating and a higher LZH level.

[21] Both Figures $3 \mathrm{~b}$ and $3 \mathrm{c}$ depict the estimated altitude of the LZH level with a black line in the lower panels. For those scenes where CloudSat detects clouds, the two estimates of the LZH level are similar, but they differ substantially where 
(a)

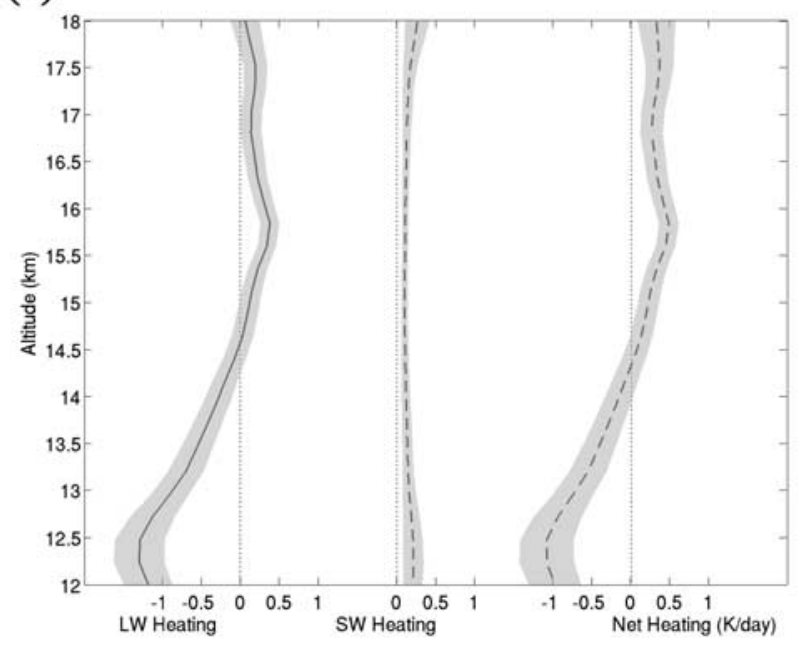

(b)

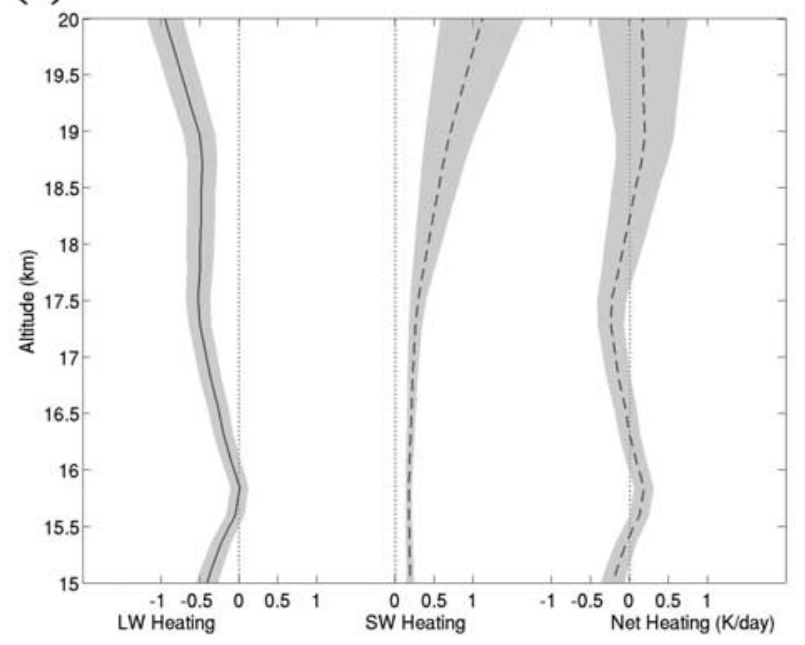

Figure 4. (a) Clear-sky longwave, shortwave, and net radiative heating rate profiles from the 2B-FLXHR product for the sample granule on 17 October 2006 , at $0116 \mathrm{UT}$ at $0^{\circ} \mathrm{N}$ and $173^{\circ} \mathrm{W}$. Shaded gray areas indicate uncertainty estimate based on approximate ECMWF uncertainty estimates in $\mathrm{T}_{1} \mathrm{H}_{2} \mathrm{O}$, and $\mathrm{O}_{3}$ profiles, and the LZH level is $14.5 \pm 0.3 \mathrm{~km}$. (b) Same as Figure 4 a but for profile at $2^{\circ} \mathrm{N}$ and $174^{\circ} \mathrm{W}$ with a cirrus layer of cloud water path $\approx 15 \mathrm{~g} / \mathrm{m}^{2}$ at $14-16 \mathrm{~km}$ with cloud water content uncertainty from 2BCWC-RO data. The LZH level is $15.5 \pm 0.5 \mathrm{~km}$.

CloudSat determines a clear-sky scene while CALIPSO detects overlying thin cirrus clouds.

[22] It is necessary to address how well CloudSat observations and ancillary data constrain understanding of the LZH level. Figure 1a shows that given assumptions about the uncertainty in ECMWF analysis products, we find that clear-sky net heating can be known to within $0.1 \mathrm{~K} /$ day. Figure 4a shows the same plot as Figure 1a, focusing on the TTL and indicates that, for clear-sky conditions, the estimated uncertainty in the auxiliary ECMWF analysis fields produces a LZH level uncertainty of approximately $\pm 0.3 \mathrm{~km}$. The presence of a high-altitude cirrus cloud impacts net heating substantially and significantly raises the LZH level to approximately $15.5 \mathrm{~km}$ as seen in Figure $4 \mathrm{~b}$. The cloud has also expanded the uncertainty in the LZH level to approximately $\pm 0.5 \mathrm{~km}$.

[23] There is significant uncertainty associated with the retrieval of CWC profiles and consequently of net heating rate profiles in the vicinity of clouds. We seek to address the importance of CWC profile uncertainties in the determination of the LZH level. We assume that the uncertainty in CWC is a constant percentage of the total CWC retrieval value for each layer. Then, we vary the $\mathrm{CWC}$ value and determine the corresponding variability in the LZH level.

[24] CloudSat and CALIPSO measurements provide a strong constraint on the vertical distribution of cloud features. However, there is significant uncertainty in the retrieved values for cloud water content and particle size distribution and phase information from the radar reflectivity and backscatter data respectively. Figure 5 shows the uncertainty in the LZH level as a function of the uncertainty in CWC profiles for three different scenarios with an underlying Tropical Model Atmosphere: a 1-km-thick liquid cloud spanning 4-5 km, a 2-km-thick ice cloud spanning $10-12 \mathrm{~km}$, and a $1-\mathrm{km}$-thick liquid cloud spanning $4-5 \mathrm{~km}$ underlying a 2-km-thick ice cloud spanning $10-12 \mathrm{~km}$. For each point on each curve, we fixed the cloud height but varied the cloud water content to explore how CWC influences LZH given that CloudSat describes cloud height distribution very well. Where low-level liquid clouds are present, the LZH altitude is well-constrained by CloudSat. Where ice clouds are present, even with significant uncertainty in the liquid and ice water content values retrieved from CloudSat measurements, the CWC approximation only contributes to an uncertainty in the LZH level of approximately $0.5 \mathrm{~km}$. Therefore, it is reasonable to conclude that the specification of the vertical distribution of clouds from CloudSat, even with large CWC retrieval uncertainty, is useful for determining the LZH level.

\section{Use of Passive Sounders}

[25] Given the wealth of instrumentation in the A-Train, it may be possible to supplement along-track information pertaining to LZH distribution from active sounders with cross-track information from passive sounders. For example, AIRS is a hyperspectral thermal IR sounder and AMSR-E [Kawanishi et al., 2003] is a 6-channel passive microwave sounder. Both instruments reside aboard the polar-orbiting Aqua platform, which flies in close formation with the CloudSat platform. These instruments have nearly collocated ground footprints that have recorded measurements since mid-2002 with a retrieved product spatial resolution of $45 \mathrm{~km}$. Retrieval products from AIRS include $\mathrm{T}, \mathrm{H}_{2} \mathrm{O}$, and $\mathrm{O}_{3}$ profiles in addition to information on cloud top height (CTH). AMSR-E data processing algorithms generate a cloud water path (CWP) product over ocean scenes [i.e., Huang et al., 2006]. These standard L2 and L3 products may be utilized to derive information about the heating/cooling rate profile in most scenes. Although CloudSat and CALIPSO provide much greater vertical 


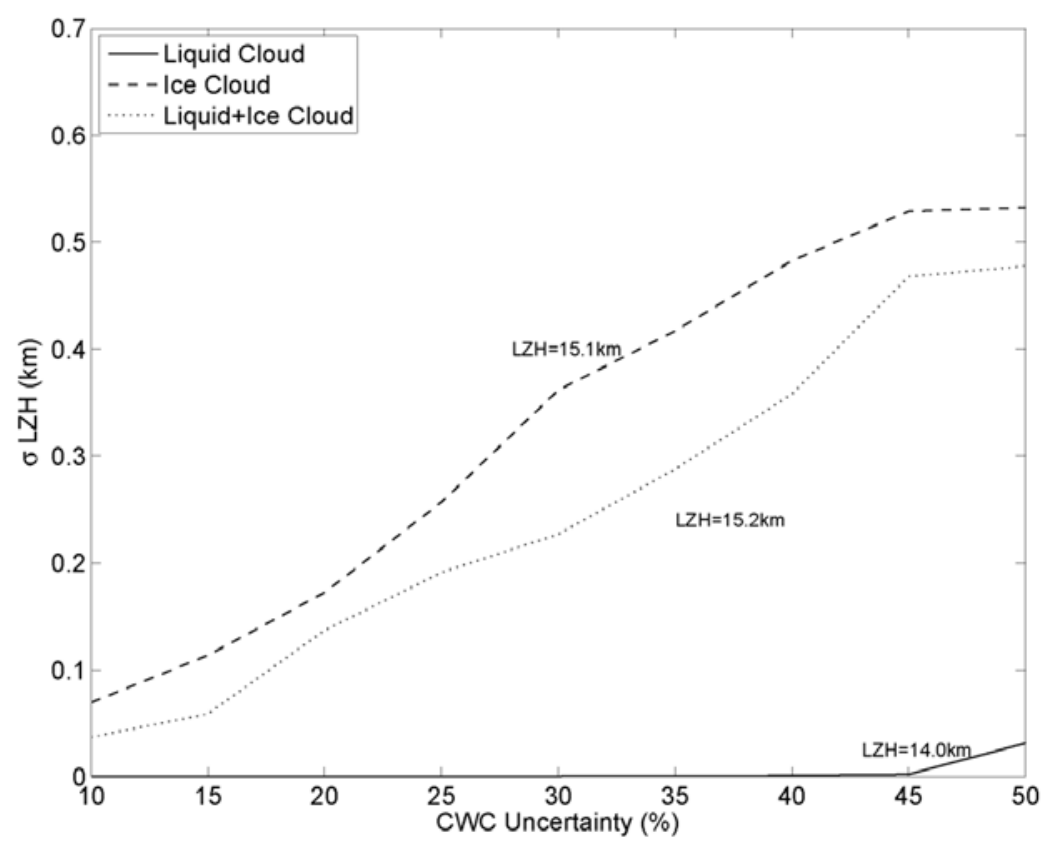

Figure 5. Standard deviation of LZH level as a function of cloud water content uncertainty for scenarios with an ice cloud from 10 to $12 \mathrm{~km}$ with effective radius $\mathrm{R}_{\mathrm{e}}=41.5 \mu \mathrm{m}$ and $\mathrm{IWC}=4.8 \mathrm{mg} / \mathrm{m}^{3}$, a liquid cloud $4-5 \mathrm{~km}$ with $\mathrm{R}_{\mathrm{e}}=6.2 \mu \mathrm{m}$ and $\mathrm{LWC}=280 \mathrm{mg} / \mathrm{m}^{3}$, and a scenario with both such liquid and ice clouds overlapping.

information, they are limited to nadir sounding with very limited pointing capability.

[26] The issue of whether LZH can be determined adequately despite a posteriori uncertainties in $\mathrm{T}, \mathrm{H}_{2} \mathrm{O}$, and $\mathrm{O}_{3}$ profiles and, more importantly, the conspicuous lack of vertical cloud information needs to be addressed. The upper bound on the contribution of clouds to LZH uncertainty can be determined by varying cloud water content distribution according to CTH and CWP constraints, while $\mathrm{T}, \mathrm{H}_{2} \mathrm{O}$ and $\mathrm{O}_{3}$ errors can be incorporated according to section 2. For different $\mathrm{CTH}$ and CWP values, which can be well constrained by AIRS/AMSR-E jointly, we test to see the range

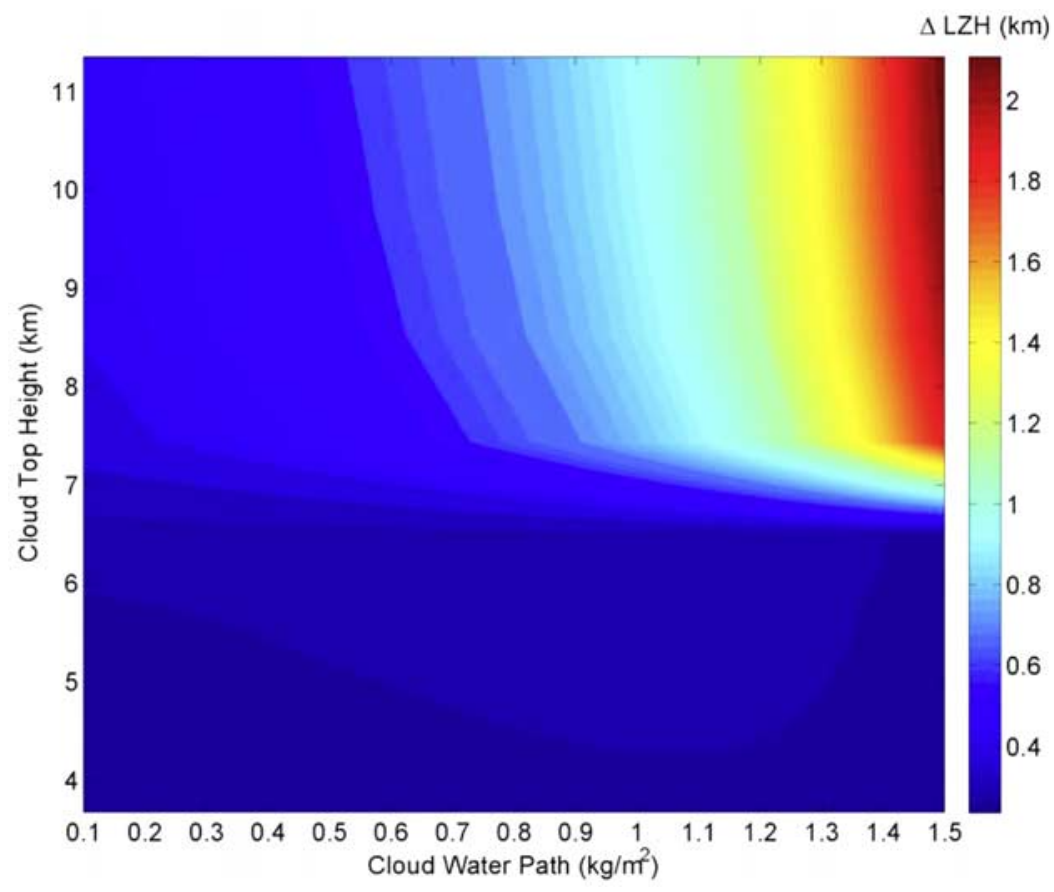

Figure 6. Uncertainty in the LZH level where CWP and CTH are constrained by AIRS/AMSR-E measurements but vertical details of cloud water content distribution are allowed to vary below the cloud top. 
(a)

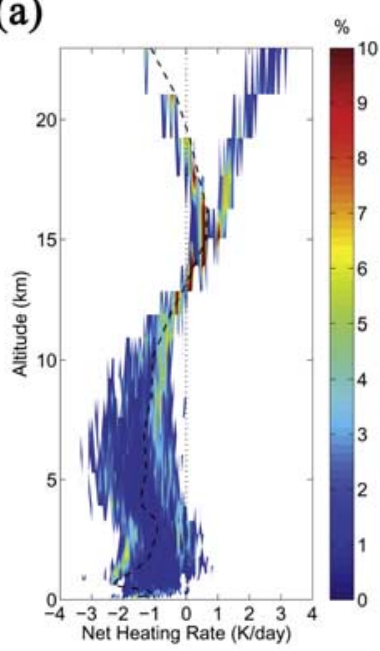

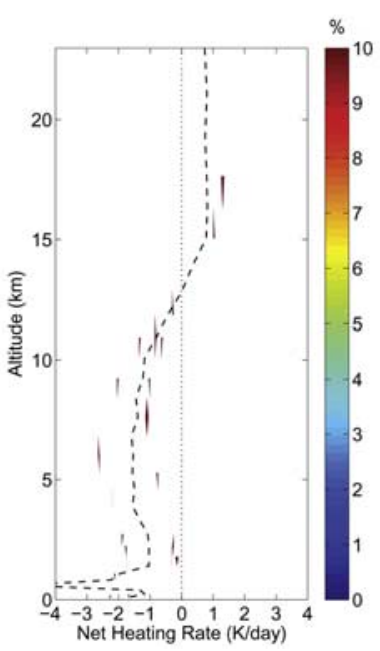

(b)

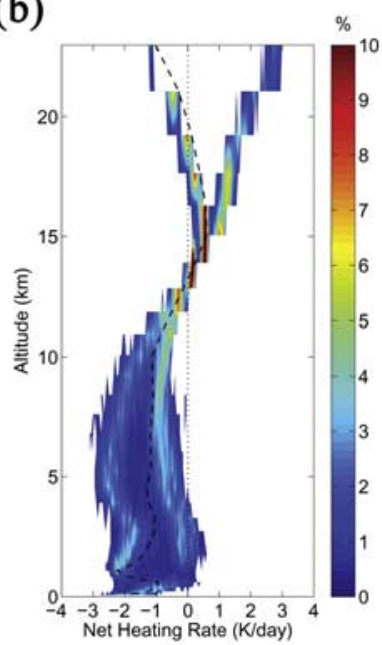

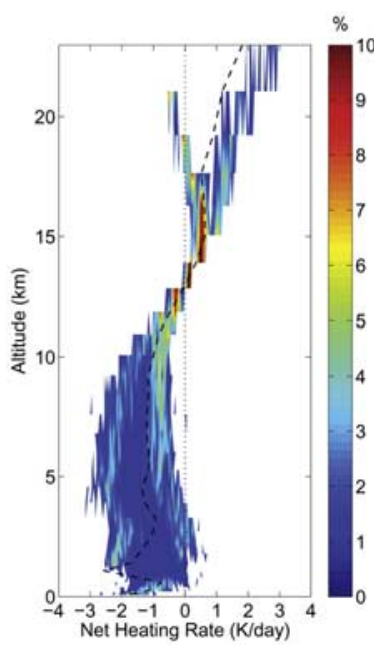

Figure 7. (a) (left) Histogram of net heating rate profiles derived from GISS ModelE data from 4x daily data for a climatological January for the box from $1^{\circ} \mathrm{S}$ to $1^{\circ} \mathrm{N}$ and $145^{\circ} \mathrm{E}$ to $151^{\circ} \mathrm{E}$. (right) Histogram of net heating rate profiles derived from a subset of GISS ModelE data that would be sampled by the CloudSat orbit over the same time period. (b) Same as Figure 7a but the data span $3^{\circ} \mathrm{S}$ to $3^{\circ} \mathrm{N}$ and $147^{\circ} \mathrm{E}$ to $149^{\circ} \mathrm{E}$. The bimodal distribution of net heating at many altitudes is indicative of the diurnal variation in shortwave heating.

in possible LZH associated with different cloud height distributions through Monte Carlo sampling using a Tropical Model Atmosphere. As seen in Figure 6, where CTH is less than $7 \mathrm{~km}$, the specification of CWP and CTH is sufficient to constrain the LZH to within several hundred meters. Where the LZH is greater than $7 \mathrm{~km}$, further knowledge about the cloud vertical distribution is necessary, except for cases with cloud water path is less than $0.2 \mathrm{~kg} / \mathrm{m}^{2}$.

[27] Since there is significant cloud occurrence frequency above $7 \mathrm{~km}$ and the variations in the LZH are strongly affected by deep convective clouds, the current suite of passive sounders in the A-Train are not likely to impart useful information toward understanding the spatial and temporal distribution of the LZH. Moreover, the CWP constraint by AMSR-E measurements is not viable over land scenes, and this precludes comprehensive LZH spatial analysis.

\section{Orbital Simulations}

[28] CloudSat provides a large amount of information content about heating rate profiles, though only along its nadir ground track. The ability of CloudSat products to describe the true two-dimensional distribution of net heating rates and the concomitant LZH can be explored through orbital simulations. Here, synthetic data are produced by using GISS modelE fields [Schmidt et al., 2006]. The complete provision of fields necessary to synthesize heating and cooling rate profiles along with LZH maps allows one to test the question of whether the limited spatial coverage attendant to CloudSat observations is sufficient to reproduce the underlying PDF of heating rates and the LZH that can be ascertained from the full data set.

[29] In order to accomplish the simulation, one month's worth of CloudSat footprints are interpolated to a $2 \times 2.5^{\circ}$ latitude/longitude grid. The data from the GISS model fields corresponding to the nearest satellite footprint are input into a RRTM calculation from which the LZH is estimated. The data subset is used to create frequency distributions of net heating rate profiles. The distribution derived from the orbital coverage (assuming CloudSat is able to determine heating rates perfectly) is compared to the underlying distribution of net heating rates. These results, as seen in Figures $7 \mathrm{a}$ and $7 \mathrm{~b}$, demonstrate that, on a monthly timescale, CloudSat measurements are not quite sufficient for representing the underlying net heating distribution, but for a latitude/longitude grid box of $6^{\circ} \times 5^{\circ}$, these measurements may be adequate for capturing the underlying statistics.

[30] The results indicate that for a low-resolution spatial grid of $6^{\circ} \times 5^{\circ}$, CloudSat is likely able to reproduce well the underlying net heating rate distribution and the associated LZH (which in this case is around $14 \mathrm{~km}$ ) on a monthly timescale. However, at the same time, the orbital simulation test shown in Figure $7 \mathrm{~b}$ indicates that nadir sounding measurements will have difficulty in capturing the underlying distribution net heating for a $2^{\circ} \times 2^{\circ}$ grid box because of the limited number of CloudSat overpasses. Nevertheless, Figure $7 \mathrm{~b}$ also shows that it is likely that CloudSat would be able to reproduce the mean net heating rate profile with a small number of samples.

\section{CloudSat Zero Net Heating Distribution}

[31] Given the long residence times of parcels in the TTL [e.g., Hartmann et al., 2001], it is important to characterize the spatial distribution of LZH values, because this distribution may describe which regions are having the most influence on stratospheric hydration. Although CloudSat 2B-FLXHR data has been released covering only 1.5 years, preliminary maps of the zonal LZH occurrence frequency can be produced.

[32] A sample occurrence frequency for a geographic box surrounding Manus Island is shown in Figure 8 and indicates that the LZH is most likely to be around $16 \mathrm{~km}$. Strong 


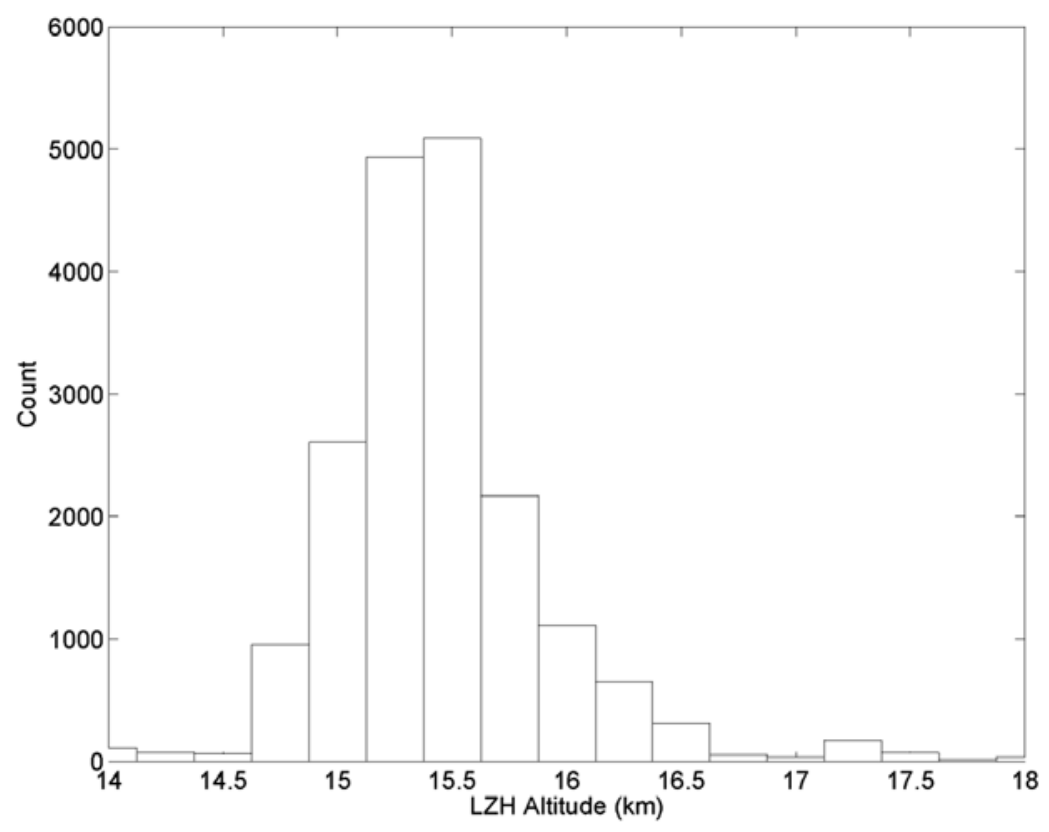

Figure 8. Histogram of LZH level values derived from CloudSat 2B-FLXHR products for July 2006 to July 2007 using daytime data in the vicinity of Manus Island (the geographic region from $3^{\circ} \mathrm{S}$ to $3^{\circ} \mathrm{N}$ and $145^{\circ} \mathrm{E}$ to $\left.150^{\circ} \mathrm{E}\right)$. The mean $\mathrm{LZH}$ value is $15.5 \mathrm{~km}$.

convective events can push the level higher, though it is unlikely to be above $18 \mathrm{~km}$. Figure 8 also shows that the LZH values for this region essentially have a bimodal distribution. Figure 9 shows the zonal variation in $\mathrm{LZH}$ occurrence frequency in meridionally averaged equatorial bands and has several salient features. First, LZH values are generally higher for this period in the tropical western Pacific Ocean (TWP), as compared to the tropical eastern Pacific Ocean (TEP), and this result is consistent with findings of others regarding this level [Gettelman and Forster, 2002]. Second, the distribution of LZH values is slightly broader in the TWP than in the TEP suggesting that strong convective

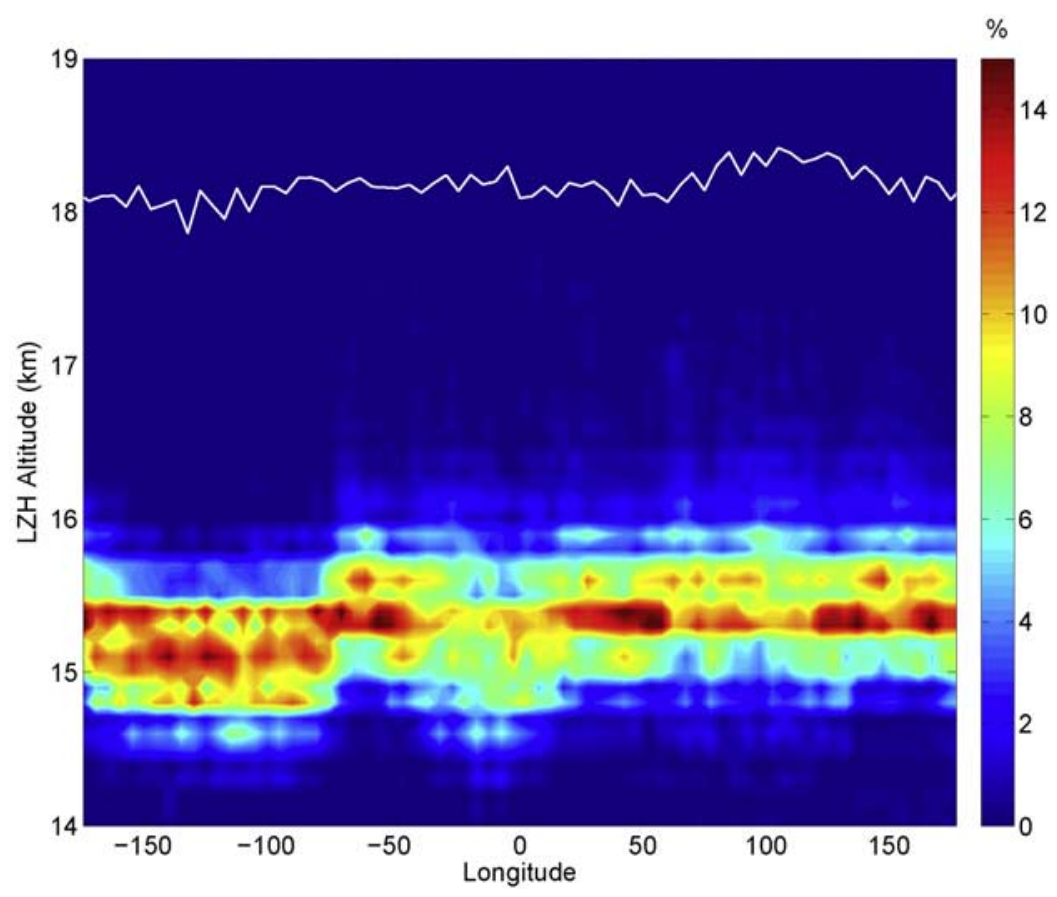

Figure 9. Zonal variation in occurrence frequency of LZH level values derived from CloudSat 2B-FLXHR data from July 2006 to July 2007 for the latitude band from $2.5^{\circ} \mathrm{S}$ to $2.5^{\circ} \mathrm{N}$. The overlying white line indicates the mean cold-point tropopause derived from ECMWF analysis data. 
(a)
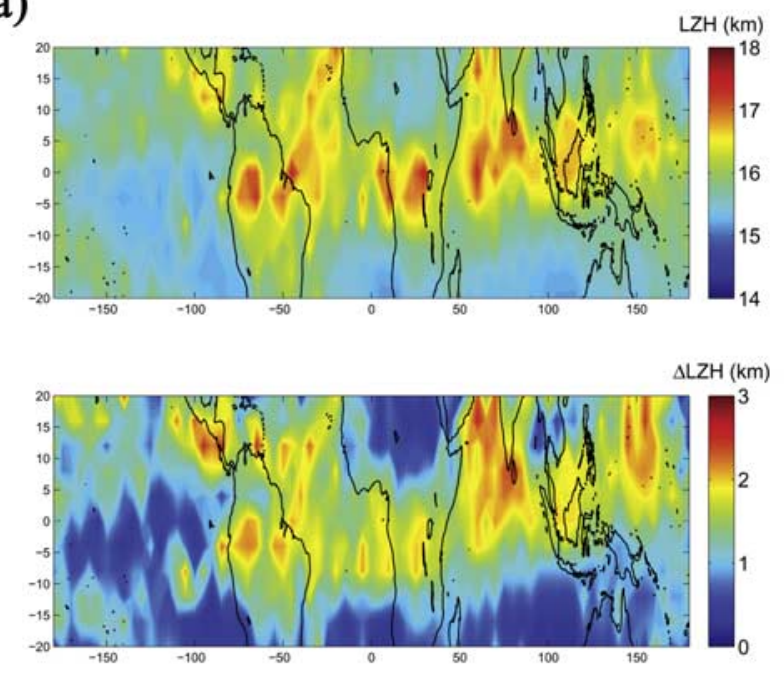

(b)
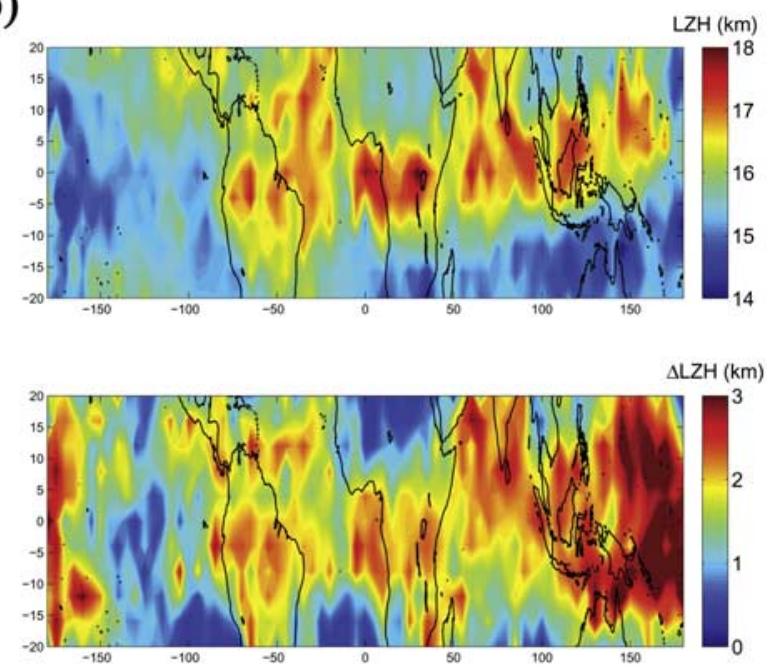

(c)
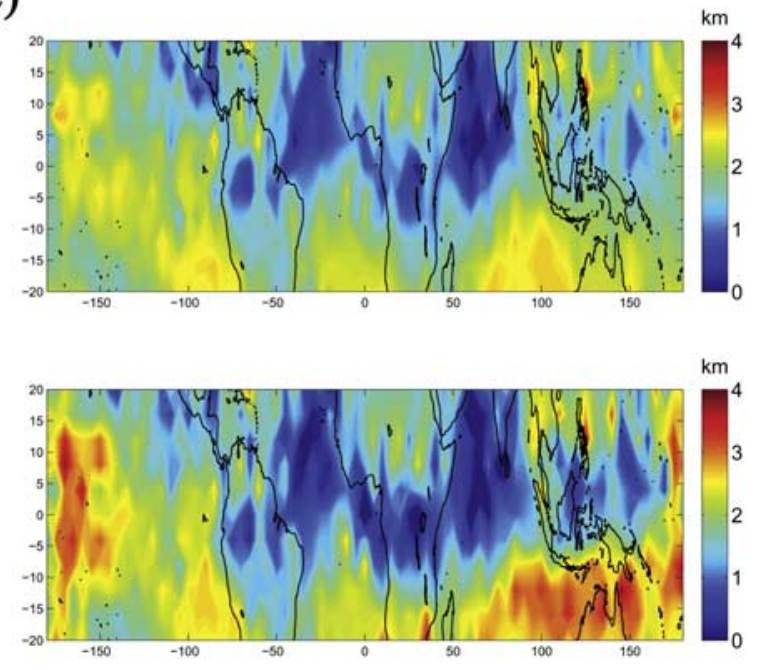

Figure 10. (a) (top) Monthly mean and (bottom) standard deviation LZH maps at $4 \times 5^{\circ}$ resolution derived from CloudSat 2B-FLXHR product results for December 2006 to February 2007. (b) Same plot derived from 2B-FLXHR-LIDAR product results. (c) Mean TTL thickness (CPT-LZH) derived from (top) the 2B-FLXHR data and (bottom) the 2B-FLXHR-LIDAR data.

processes are differentially affecting TWP and TEP TTL radiation balance.

[33] Mean and standard deviation LZH maps can also be useful for determining the zonal and meridional variation in this quantity. Figures $10 \mathrm{a}$ and $10 \mathrm{~b}$ show the spatial distribution of mean LZH values and their standard deviations for December 2006 to February 2007 (DJF), respectively, and the associated variation of these values. Figure 10a shows the equivalent results derived from the 2B-FLXHR product, while Figure $10 \mathrm{~b}$ displays the results from the 2B-FLXHRLIDAR product. At a resolution of $4^{\circ} \times 5^{\circ}$, the seasonal mean TTL radiation balance derived from the two different data sets are generally in good agreement, although some minor differences are evident, particularly in regions of deep convection where the $2 \mathrm{~B}-\mathrm{FLXHR}$ product tends to underestimate the LZH level. More significantly, differences exist in the estimated standard deviation in $\mathrm{LZH}$, where the 2B-
FLXHR-LIDAR data indicate much larger variations throughout the tropics indicative of the greater variability introduced by thin cirrus that are not resolved by CloudSat. Finally, Figure 10c shows the approximate thickness of the TTL derived from CloudSat and CALIPSO measurements as determined by the difference cold-point tropopause height (derived from ECWMF analysis data) and the altitude of the LZH. Figure 10c shows that the thickness of the TTL for parcel residence and transport purposes is strongly affected by the presence of clouds and varies from just a few hundred meters to several kilometers. Also, it should be noted that the TTL thickness determined by CloudSat measurements differs from that derived from the combined product of CloudSat and CALIPSO. The 2B-FLXHR-LIDAR product has a higher $\mathrm{LZH}$ in the regions of strongest convection which is expected given the sensitivity of CALIPSO to thin clouds. 
Also, this product yields a lower LZH away from the strong convection partly due to the product's treatment of thin clouds at lower altitudes: the assumptions made regarding the optical properties of clouds missed by CloudSat lead to large flux divergence at lower altitudes and slightly diminished cooling by upper tropospheric water vapor.

[34] Only some of the spatial and temporal LZH details derived from CloudSat data are described by the radiosonde data set. Satellite-based remote sensing of TTL radiation balance has significant descriptive power over the equatorial Atlantic Ocean, the Indian Ocean, and the TEP. Still, where collocation occurs, LZH maps derived from CloudSat data agree with those derived from radiosonde observations [i.e., Gettelman and Forster, 2002]. Ultimately, it is important to incorporate the remote sensing data on heating rates into a model of stratospheretroposphere exchange to understand how data-driven knowledge of the level of zero radiative heating impacts understanding of the relative importance of different mechanisms for controlling stratosphere-troposphere exchange of water vapor.

\section{Conclusions}

[35] Active sounding of the vertical distribution of clouds from CloudSat introduces significant information for understanding vertical net heating rate profiles. Given ancillary information including temperature, water vapor, and ozone profiles from other instruments or forecast analyses, the spatial distribution of net heating rates can be described to within $0.1 \mathrm{~K} / \mathrm{d}$ for clear-sky scenes. With CloudSat's retrieval of cloud properties, cloud heating rates are known to within several $\mathrm{K} / \mathrm{d}$, though the large uncertainties in the retrieval of cloud water content and effective radius currently renders instantaneous estimates of in-cloud heating rates difficult to resolve.

[36] The longwave and shortwave fluxes and heating rate products have broad application to model-measurement comparisons and can be used directly to analyze the level of zero net radiative heating in the Tropical Tropopause Layer. This LZH level is a dividing line that determines parcel ascent or descent and should be well characterized in the course of discussions of the relative roles of different processes in hydrating the stratosphere. Given that passive remote sensing information can generally constrain the level of zero net heating where the cloud top height is less than $7 \mathrm{~km}$, the introduction of active sounding information is very valuable toward LZH level analysis. We have analyzed 1 year's worth of CloudSat 2B-FLXHR products and derived information about the spatial and temporal distribution of the LZH level. The LZH differences between the 2B-FLXHR product and the 2B-FLXHR-LIDAR product for December 2006 through February 2007 are minor, and suggest that the usage of the CALIPSO lidar data is most important for the determination of the variability in the LZH level. The results also suggest that the effect of deep convective clouds on the radiative balance of the TTL is significant throughout the tropics. Further analysis will require integration of data-driven heating rate information into TTL models. The continued refinement of the 2B-FLXHR product (including formal integration of the CALIPSO measurements), along with the increasing data volume will allow for a more thorough characterization of the LZH level.

[37] The CloudSat 2B-FLXHR product contains datadriven heating rates and fluxes which will be scientifically meaningful to the extent that they can be validated. Using surface and top-of-atmosphere broadband flux measurements from CERES [Wielicki et al., 1996] provides a first-order test of validity [L'Ecuyer et al., 2008]. However, it would be useful first to analyze the CloudSat validation experiments (e.g., the CloudSat/CALIPSO Validation Experiment: see http://angler.larc.nasa.gov/ccvex/ for details) in terms of heating rates and fluxes, and second to consider the inclusion of in situ flux measurements [e.g., Asano and Yoshida, 2004; Mlynczak and Johnson, 2006] in such campaigns. Such data would allow for further CloudSat algorithm development, especially to address in-cloud heating rates, which are presently difficult to characterize with remote sensing measurements.

[38] Acknowledgments. This research was supported by the NASA Earth Systems Science Fellowship, grant NNG05GP90H. Invaluable technical support was provided by Tony Clough, Mark Iacono, and Mark Shepard at AER, Inc. The authors would also like to acknowledge the help provided by Jonathan Jiang, Duane Waliser, Brian Kahn, and Frank Li at NASA JPL, Tony Del Genio at NASA GISS, Sally McFarlane of PNNL, Zhiming Kuang of Harvard, and the Yuk Yung Radiation Group including Jack Margolis, Vijay Natraj, Kuai Le, and King-Fai Li. Additionally, the two anonymous reviewers for the paper provided very useful advice. Finally, the CloudSat Data Processing Team provided crucial technical support.

\section{References}

Asano, S., and Y. Yoshida (2004), Development of a radiometer-sonde for simultaneously measuring the downward and upward broadband fluxes of shortwave and longwave radiation, J. Meteorol. Soc. Jpn., 82, 623-637, doi:10.2151/jmsj.2004.623.

Asrar, G., and J. Dozier (1994), EOS: Science Strategy for the Earth Observing System, 128 pp., Am. Inst. of Phys., Melville, N. Y.

Aumann, H. H., et al. (2003), AIRS/AMSU/HSB on the aqua mission: Design, science objectives, data products, and processing systems, IEEE Trans. Geosci. Remote Sens., 41, 253-264, doi:10.1109/TGRS. 2002.808356.

Austin, R. T., and G. L. Stephens (2001), Retrieval of stratus cloud microphysical parameters using millimeter-wave radar and visible optical depth in preparation for CloudSat - 1. Algorithm formulation, J. Geophys. Res., 106, 28,233-28,242, doi:10.1029/2000JD000293.

Baer, D. S., et al. (2002), Sensitive absorption measurements in the nearinfrared region using off-axis integrated-cavity-output spectroscopy, Appl. Phys. B, 75, 261-265, doi:10.1007/s00340-002-0971-z.

Benedetti, A., G. L. Stephens, and J. M. Haynes (2003), Ice cloud microphysics retrievals from millimeter radar and visible optical depth using an estimation theory approach, J. Geophys. Res., 108(D11), 4335, doi:10.1029/2002JD002693.

Clough, S. A., et al. (1989), Line shape and water vapor continuum, Atmos. Res., 23, 229-241, doi:10.1016/0169-8095(89)90020-3.

Clough, S. A., et al. (2005), Atmospheric radiative transfer modeling: A summary of the AER codes, J. Quant. Spectrosc. Radiat. Transfer, 91, 233-244, doi:10.1016/j.jqsrt.2004.05.058.

Corti, T., B. P. Luo, T. Peter, H. Vömel, and Q. Fu (2005), Mean radiative energy balance and vertical mass fluxes in the equatorial upper troposphere and lower stratosphere, Geophys. Res. Lett., 32, L06802, doi:10.1029/2004GL021889.

Feldman, D. R., K. N. Liou, R. L. Shia, and Y. L. Yung (2008), On the information content of the thermal infrared cooling rate profile from satellite instrument measurements, J. Geophys. Res., 113, D11118, doi:10.1029/2007JD009041.

$\mathrm{Fu}$, Q., et al. (1997), Multiple scattering parameterization in thermal infrared radiative transfer, J. Atmos. Sci., 54, 2799-2812, doi:10.1175/ 1520-0469(1997)054<2799:MSPITI>2.0.CO;2.

Fueglistaler, S., and Q. Fu (2006), Impact of clouds on radiative heating rates in the tropical lower stratosphere, J. Geophys. Res., 111, D23202, doi:10.1029/2006JD007273.

Fueglistaler, S., et al. (2007), Towards a synthesis definition of the TTL, Geophys. Res. Abstr., 9, 06470. 
Gettelman, A., and T. Birner (2007), Insights into tropical tropopause layer processes using global models, J. Geophys. Res., 112, D23104, doi:10.1029/2007JD008945.

Gettelman, A., and P. M. D. Forster (2002), A climatology of the tropical tropopause layer, J. Meteorol. Soc. Jpn., 80, 911-924, doi:10.2151/ jmsj.80.911.

Gettelman, A., P. M. de F. Forster, M. Fujiwara, Q. Fu, H. Vömel, L. K. Gohar, C. Johanson, and M. Ammerman (2004), Radiation balance of the tropical tropopause layer, J. Geophys. Res., 109, D07103, doi:10.1029/ 2003JD004190.

Hartmann, D. L., J. R. Holton, and Q. Fu (2001), The heat balance of the tropical tropopause, cirrus, and stratospheric dehydration, Geophys. Res. Lett., 28, 1969-1972, doi:10.1029/2000GL012833.

Highwood, E. J., and B. J. Hoskins (1998), The tropical tropopause, Q. J. R. Meteorol. Soc., 124, 1579-1604, doi:10.1002/qj.49712454911.

Holton, J. R., and A. Gettelman (2001), Horizontal transport and the dehydration of the stratosphere, Geophys. Res. Lett., 28, 2799-2802, doi:10.1029/2001GL013148.

Holton, J. R., P. H. Haynes, M. E. McIntyre, A. R. Douglass, R. B. Rood, and L. Pfister (1995), Stratosphere-troposphere exchange, Rev. Geophys., 33, 403-439, doi:10.1029/95RG02097.

$\mathrm{Hu}$, Y. X., and K. Stamnes (1993), An accurate parameterization of the radiative properties of water clouds suitable for use in climate models, J. Clim., 6, 728-742, doi:10.1175/1520-0442(1993)006 $<0728$ :AAPOTR $>2.0 . \mathrm{CO} ; 2$.

Huang, J. P., P. Minnis, B. Lin, Y. Yi, T.-F. Fan, S. Sun-Mack, and J. K. Ayers (2006), Determination of ice water path in ice-over-water cloud systems using combined MODIS and AMSR-E measurements, Geophys. Res. Lett., 33, L21801, doi:10.1029/2006GL027038.

Kawanishi, T., et al. (2003), The Advanced Microwave Scanning Radiometer for the Earth Observing System (AMSR-E), NASDA's contribution to the EOS for global energy and water cycle studies, IEEE Trans. Geosci. Remote Sens., 41, 184-194, doi:10.1109/TGRS.2002.808331.

Kay, J. E., T. L'Ecuyer, A. Gettelman, G. Stephens, and C. O'Dell (2008), The contribution of cloud and radiation anomalies to the 2007 Arctic sea ice extent minimum, Geophys. Res. Lett., 35, L08503, doi:10.1029/ 2008GL033451.

L'Ecuyer, T. S., N. B. Wood, T. Haladay, G. L. Stephens, and P. W. Stackhouse Jr. (2008), The impact of clouds on the atmospheric radiation budget in the R04 CloudSat fluxes and heating rates data set, J. Geophys. Res., doi:10.1029/2008JD009951, in press.

Mace, G. G., R. Marchand, Q. Zhang, and G. Stephens (2007), Global hydrometeor occurrence as observed by CloudSat: Initial observations from summer 2006, Geophys. Res. Lett., 34, L09808, doi:10.1029/ 2006 GL029017.

Marchand, R., et al. (2008), Hydrometeor detection using CloudSatAn Earth-orbiting 94-GHz cloud radar, J. Atmos. Oceanic Technol., 25, 519-533, doi:10.1175/2007JTECHA1006.1.

Mather, J. H., S. A. McFarlane, M. A. Miller, and K. L. Johnson (2007), Cloud properties and associated radiative heating rates in the tropical western Pacific, J. Geophys. Res., 112, D05201, doi:10.1029/2006JD007555.

May, R. D. (1998), Open-path, near-infrared tunable diode laser spectrometer for atmospheric measurements of $\mathrm{H} 2 \mathrm{O}$, J. Geophys. Res., 103, 19,161-19,172, doi:10.1029/98JD01678.

McFarlane, S. A., J. H. Mather, and T. P. Ackerman (2007), Analysis of tropical radiative heating profiles: A comparison of models and observations, J. Geophys. Res., 112, D14218, doi:10.1029/2006JD008290.

McFarquhar, G. M., and A. J. Heymsfield (1997), Parameterization of tropical cirrus ice crystal size distributions and implications for radiative transfer: Results from CEPEX, J. Atmos. Sci., 54, 2187-2200, doi:10.1175/1520-0469(1997)054<2187:POTCIC>2.0.CO;2.

Meneghini, R., and T. Kozu (1990), Spaceborne Weather Radar, 208 pp., Artech House, Boston, Mass.

Michelsen, H. A., F. W. Irion, G. L. Manney, G. C. Toon, and M. R. Gunson (2000), Features and trends in Atmospheric Trace Molecule Spectroscopy (ATMOS) version 3 stratospheric water vapor and methane measurements, J. Geophys. Res., 105, 22,713-22,724, doi:10.1029/ 2000JD900336.

Mlawer, E. J., S. J. Taubman, P. D. Brown, M. J. Iacono, and S. A. Clough (1997), Radiative transfer for inhomogeneous atmospheres: RRTM, a validated correlated-k model for the longwave, J. Geophys. Res., 102, 16,663-16,682, doi:10.1029/97JD00237.

Mlynczak, M. G., and D. G. Johnson (2006), INFLAME: In-situ net flux within the atmosphere of the Earth, Eos Trans. $A G U, 87(52)$, Fall Meet. Suppl., Abstract IN23B-04.

Norton, W. A. (2001), Longwave heating of the tropical lower stratosphere, Geophys. Res. Lett., 28, 3653-3656, doi:10.1029/2001GL013379.

Paul, J. B., et al. (2001), Ultrasensitive absorption spectroscopy with a highfinesse optical cavity and off-axis alignment, Appl. Opt., 40, 4904-4910, doi:10.1364/AO.40.004904.

Platnick, S., et al. (2003), The MODIS cloud products: Algorithms and examples from Terra, IEEE Trans. Geosci. Remote Sens., 41, 459-473, doi:10.1109/TGRS.2002.808301.

Rabier, F., et al. (1998), Extended assimilation and forecast experiments with a four-dimensional variational assimilation system, Q. J. R. Meteorol. Soc., 124, 1861-1887, doi:10.1002/qj.49712455005.

Rodgers, C. D. (2000), Inverse Methods for Atmospheric Sounding: Theory and Practice, 238 pp., World Sci., London.

Rosenlof, K. H., et al. (2001), Stratospheric water vapor increases over the past half-century, Geophys. Res. Lett., 28, 1195-1198, doi:10.1029/ 2000GL012502.

Schmidt, G. A., et al. (2006), Present-day atmospheric simulations using GISS ModelE: Comparison to in situ, satellite, and reanalysis data, J. Clim., 19, 153-192, doi:10.1175/JCLI3612.1.

Sherwood, S. C., and A. E. Dessler (2000), On the control of stratospheric humidity, Geophys. Res. Lett., 27, 2513-2516, doi:10.1029/ 2000GL011438.

Sherwood, S. C., and A. E. Dessler (2001), A model for transport across the tropical tropopause, J. Atmos. Sci., 58, 765-779, doi:10.1175/15200469(2001)058<0765:AMFTAT $>2.0$. CO; 2 .

Sherwood, S. C., et al. (2003), Convective impact on temperatures observed near the tropical tropopause, J. Atmos. Sci., 60, 1847-1856, doi:10.1175/ 1520-0469(2003)060<1847:CIOTON>2.0.CO;2.

Stephens, G. L., et al. (2002), The CloudSat mission and the A-train: A new dimension of space-based observations of clouds and precipitation, Bull. Am. Meteorol. Soc., 83, 1771-1790, doi:10.1175/BAMS-83-12-1771.

Stokes, G. M., and S. E. Schwartz (1994), The Atmospheric Radiation Measurement (Arm) program: Programmatic background and design of the cloud and radiation test bed, Bull. Am. Meteorol. Soc., 75, $1201-$ 1221, doi:10.1175/1520-0477(1994)075<1201:TARMPP>2.0.CO;2.

Taylor, B. N. and C. E. Kuyatt (1994), Guidelines for evaluating and expressing the uncertainty of NIST measurement results, Tech. Note 1297, Natl. Inst. of Standards and Technol., Gaithersburg, Md. (Available at http://www.physics.nist.gov/Pubs/guidelines/contents.html)

Vömel, H., D. E. David, and K. Smith (2007), Accuracy of tropospheric and stratospheric water vapor measurements by the cryogenic frost point hygrometer: Instrumental details and observations, J. Geophys. Res., 112, D08305, doi:10.1029/2006JD007224.

Webster, C. R., et al. (1994), Aircraft (ER-2) Laser Infrared-Absorption Spectrometer (ALIAS) for in-situ stratospheric measurements of $\mathrm{HCl}$, $\mathrm{N}_{2} \mathrm{O}, \mathrm{CH}_{4}, \mathrm{NO}_{2}$, and $\mathrm{HNO}_{3}$, Appl. Opt., 33, 454-472.

Weinstock, E. M., et al. (1994), New fast-response photofragment fluorescence hygrometer for use on the NASA ER-2 and the Perseus remotely piloted aircraft, Rev. Sci. Instrum., 65, 3544-3554, doi:10.1063/ 1.1144536.

Wielicki, B. A., et al. (1996), Clouds and the earth's radiant energy system (CERES): An Earth observing system experiment, Bull. Am. Meteorol. Soc., 77, 853-868, doi:10.1175/1520-0477(1996)077<0853: CATERE $>2.0 . \mathrm{CO} ; 2$.

Winker, D. M., et al. (2003), The CALIPSO mission: Spaceborne lidar for observation of aerosols and clouds, Proc. SPIE, 4893, 1-11, doi:10.1117/ 12.466539 .

D. R. Feldman and Y. L. Yung, Division of Geological and Planetary Sciences, California Institute of Technology, 1200 East California Boulevard, MC 150-21, Pasadena, CA 91125, USA. (feldman@caltech.edu)

T. S. L'Ecuyer, Department of Atmospheric Science, Colorado State University, 1371 Campus Delivery, Fort Collins, CO 80523-1371, USA.

K. N. Liou, Department of Atmospheric and Oceanic Sciences, University of California, Los Angeles, CA 90095-1565, USA. 